\title{
Effect of orifice geometry and orifice to test section spacing on distribution of wall static pressure on a convex surface
}

\author{
Anilkumar M. Hanchinal ${ }^{1}$ and Vadiraj V. Katti ${ }^{2}$ \\ ${ }^{1}$ Assistant Professor, Dept. of Mechanical Engg. \\ KLE Institute of Technology, Hubballi, Karnataka, India-580030 \\ Phone: +91-9740169907 \\ "Email: anilmh.mech@gmail.com \\ ${ }^{2}$ Principal, KLS VDIT, Haliyal, Karnataka, India-581329 \\ Email: vadiraj.katti@gmail.com
}

\begin{abstract}
The experimental study is carried to analyse the wall static pressure profile $\left(C_{p} \& C_{p o}\right)$ on the smooth convex test section by air jet impingement. A great deal of attention is given to analysing the effect of orifice geometry and orifice-to-test section for various flow and geometric conditions, a comparison of the wall static pressure coefficient is done for the different orifice. The result highlights the wall static pressure $\left(C_{p}\right)$ distribution on a convex test section is higher for rectangular orifice compared to other orifice used in the study. Maximum $C_{p}$ is observed at the stagnation point $\left(\theta=0^{\circ}\right)$ of test section and decreases circumferentially. The $C_{p}$ and $C_{p o}$ variation for an orifice-to-test section (Z/dh) on are studied, the higher value of $C_{p}$ and $C_{p o}$ are obtained at lower $Z / d h$ for any specified jet Reynold number. Orifice profile (Circular, Square, Triangle, Rectangle), Jet Reynolds number $(R e)$, Orifice-to-convex test section spacing (Z/dh), Circumferential angle $(\theta)$, Curvature ratio $(D / d h)$ are important permeates considered in the present work
\end{abstract}

Keywords: Jet impingement; Static pressure coefficient; Orifice; Convex test section.

\section{INTRODUCTION}

Jet impingement is the flow of the fluid extracted from the different nozzles and orifices geometries with high velocity to the test section which can be flat or curved surfaces (Concave and Convex). The notable characteristics of the jet impingement are the inherent properties of simple jet flow, the high rate of momentum and mass transfer or ample mixing characteristic. In addition to this jet impingement process is an efficient method of heat transfer and has been used in effective cooling of turbine blades. Reynolds number $(R e)$, Prandtl number $(P r)$, nozzle or orifice profile $(d)$, jet-to-target spacing $(Z / d h)$, curvature ratio $(D / d)$, confinement and nozzle or orifice geometry are the key parameters that affects the performance of an impinging air jet over any test section in the analyses of heat transfer.

In the last few decades, numerous experimental and numerical works helped us to know the effect of various parameters by impingement jets on different test sections. C. Cornaro et al. [1] used $47.2 \mathrm{~mm}, 72.6 \mathrm{~mm}$ and $98.6 \mathrm{~mm}$ diameter jet tubes to impinge on semi- 
cylindrical convex surface to understand the effect of $R e$ and Curvature of test section on the heat transfer. The flow visualizations study by A. S. Fleischer at al. [2] gives detailed flow dynamics of jet impinging on a convex surface, the effect of $R e$, Jet-to-test section distance and relative curvature on the vertex initiation, vertex detachment from the convex surface and vertex break up. Experimental heat transfer physics using jet array impinging on the convex dimpled surface is revealed by S.W. Chang et al. [3], a heat transfer correlation is obtained by a regression method, which helped in the evaluations of average Nusselt numbers over dimpled surface of central jet region. The effect of $R e$ and nozzle-to-plate spacing on fluid flow and heat transfer on a flat surface is studied by impinging rectangular jet, the correlations are obtained for an average Nusselt number and turbulent intensity by D.W. Zhou, S. J. Lee. [4]. The influence of circular, rectangular and square nozzle on heat transfer on a flat surface experimentally studied by P. Gulati et al. [5] and D. Singh et al [6] used a circular cylinder, the results unfold that the heat transfer rate increases from a low $R e$ too high $R e$. Similar heat transfer characteristics are shown in a square and circular jets but $N u$ is higher for rectangular nozzle and correlation for $\mathrm{Nu}$ in terms of the $R e, h / d$ and a ratio of $R e$ to $R e$ of hydraulic diameter.

X.T. Trinh et al. [7] used a tube, a round and cross-shaped injection to impinge the hemisphere surface. Vena contraction effect and heat transfer rate is high for round injections compared to others. The comparison of experimental and computational work using 4, 6 and 12 lobed nozzle geometries for the impingement on the plate is done by Y. Karakus et al. [8]. The surface inclination also influences the heat transfer rate. S. Abraham and R.P. Vedula [9-10] used the slot and circular single and a row of jets with jet-to-jet distance 4 to 8 impinging on a convex surface at different inclinations. Vinze et al. [13] studied distribution of local effectiveness on a flat surface by impinging heated circular, triangular and square jets perpendicularly to the surface and are compared with contour results.

The most of previous work deals with heat transfer study on flat and concave surfaces using circular jets [14-18] and only a few pure study has been done on the wall static pressure [20], the main objective of present work is to study the effect of different orifice geometry and orifice to test section spacing on a pressure distribution characteristic with a different orifice configuration and orifice-to-plate spacing $(Z / d h)$ on the convex smooth surface.

\section{EXPERIMENTATION}

The schematic representation of experimental set-up for present study is shown in Figure 1. The Air blower with free air delivery of $2.3 \mathrm{~m}^{3} / \mathrm{min}$ and air pressure on $400 \mathrm{~mm}$ of water when operating under 15000rpm is used for impingement of air through a different orifice on convex cylindrical surface. The test section of inner diameter $40 \mathrm{~mm}$ and outer diameter $50 \mathrm{~mm}$ with effective length of $300 \mathrm{~mm}$. The high-pressure air coming out from blower is controlled using a pressure regulator to maintain the stable downstream pressure of 1 bar. The ball valve is used to control the flow rate and calibrated venturimeter with $C_{d} \pm 0.92$ is used to identify the jet Reynold number. Four different orifices having same orifice exit area are chosen for impingement of jet. The detailed specification of orifice used in the present study are listed in Table 1. To obtain fully developed flow at orifice exit the pipe length serving as the orifice is taken 100 times the hydraulic diameter $(d h)$. The nozzle length to diameter ratio of 83 is considered [11-12]. 


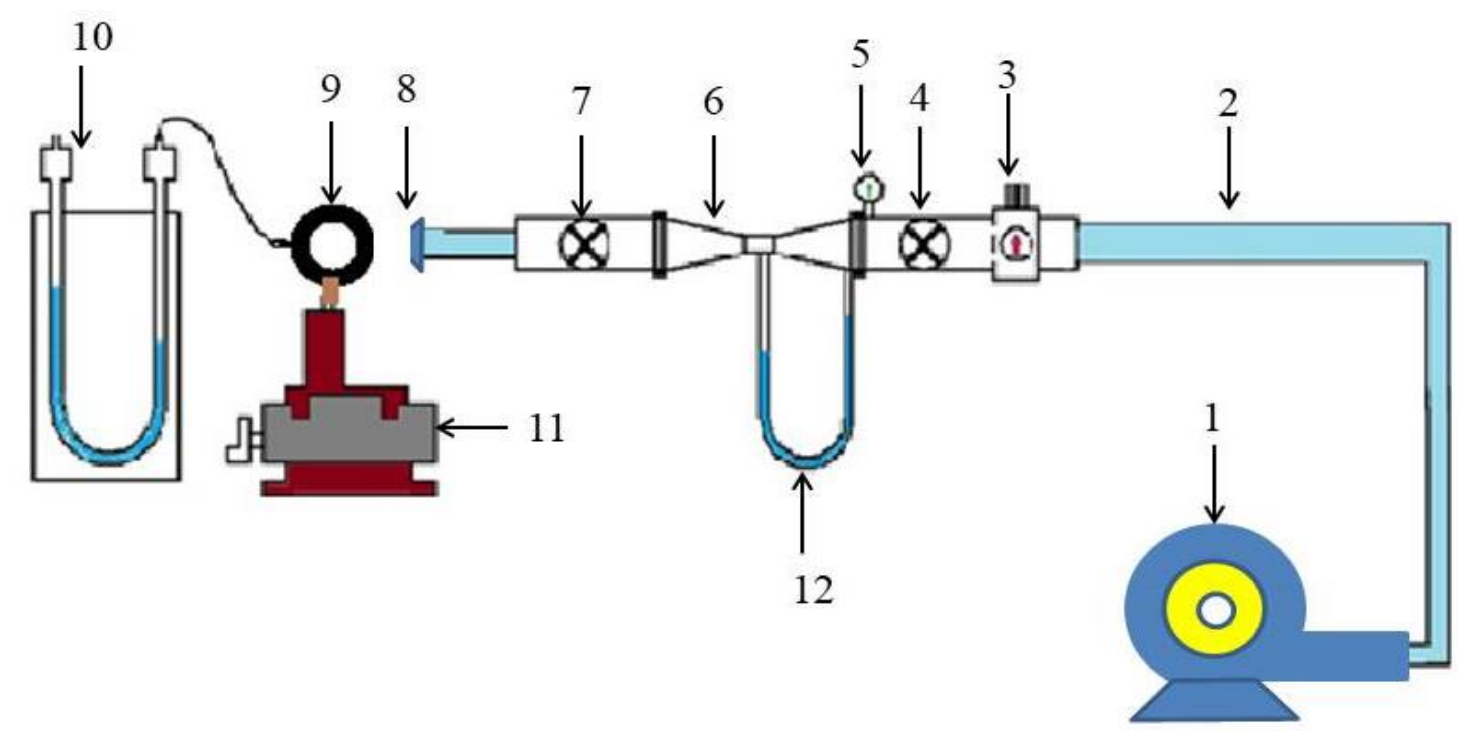

1. Blower, 2. Flexible Pipe, 3. Pressure Regulator, 4. Control Valve, 5. Pressure Gauge, 6. Venturimeter, 7. Control Valve, 8. Orifice, 9. Convex Test Section, 10. Bulb Manometer, 11. Sliding Table, 12. U Tube Manometer.

Figure 1. Schematic representation of experimental setup.

A convex test section used in the present study is mounted test section holder, a calibrated compound slide is used to adjust the test section for any particular Z/dh position. The measurement of $C_{p}$ and $C_{p o}$ on test section is done with help of pressure tap of $0.5 \mathrm{~mm}$ diameter. The circumferential wall static pressure on test section is measured with help of slider on which the pressure tap is attached. Jet and ambient temperature are measured using calibrated K-Type thermocouples with $4 \frac{1 / 2}{2}$ digital panel meter for mili voltmeter indication and this mili voltmeter reading is converted into degree Celsius by thermocouple equation. The air is blown through orifice at a particular Re and Z/dh as shown in Figure 2. In addition to all experiment is performed under a steady state at various flow and geometric condition and results are tabulated to draw different graphs for further study.

Table 1. Detailed geometry of orifice.

\begin{tabular}{ccccc}
\hline $\begin{array}{c}\text { Type of } \\
\text { nozzle }\end{array}$ & $\begin{array}{c}\text { Breadth } \\
(\mathrm{mm})\end{array}$ & $\begin{array}{c}\text { Height } \\
(\mathrm{mm})\end{array}$ & $\begin{array}{c}\text { Equivalent diameter } \\
d_{e}(\mathrm{~mm})\end{array}$ & $\begin{array}{c}\text { Hydraulic diameter } \\
d h(\mathrm{~mm})\end{array}$ \\
\hline & - & - & 16 & 16 \\
& 22 & 18 & 15.9 & 12.34 \\
\hline & 14.2 & 14.2 & 16.02 & 14.2 \\
\hline & 20 & 10 & 15.96 & 13.34 \\
\hline
\end{tabular}




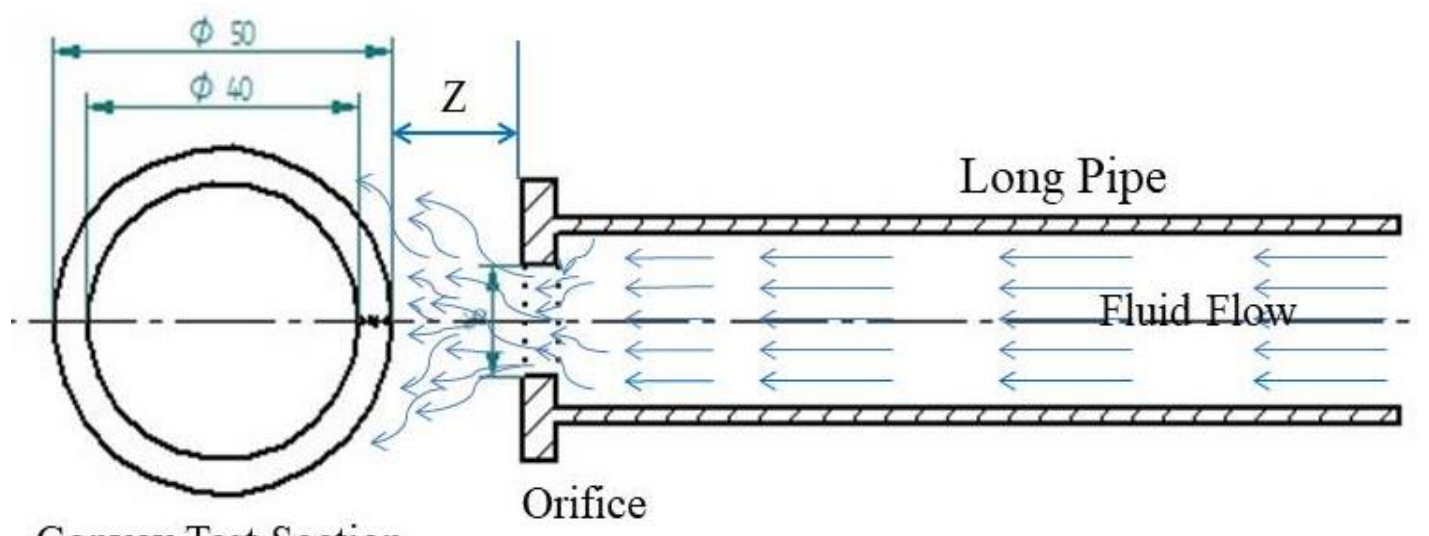

Convex Test Section

Figure 2. Schematic view of flow of jet on convex test section.

Table 2. Parameters considered in the study.

\begin{tabular}{cccc}
\hline Test Section & $\begin{array}{c}\text { Jet Reynolds } \\
\text { Number } R e\end{array}$ & $\begin{array}{c}\text { Circumferential } \\
\text { angle } \theta\end{array}$ & $\begin{array}{c}\text { Orifice to test } \\
\text { section } Z / d\end{array}$ \\
\hline $\begin{array}{c}\text { Convex Smooth } \\
\text { Surface }\end{array}$ & 10000 to 50000 & $0^{\circ}$ to $30^{\circ}$ & 1 to 5 \\
\hline
\end{tabular}

\section{RESULT AND DISCUSSION}

Jet impingement on convex test surface is extensively studied experimentally. The various flow and geometric parameters are considered are given in Table 2 and experiments are conducted under study state condition to measure of wall static pressure coefficient and further analyses are made for better understanding of the effect of orifice geometry and orifice-to-test section spacing $(Z / d h)$.

Influence of Reynolds number $(R e)$ on wall static pressure.

The Reynolds number is a parameter helps to identify the flow condition of the fluid. The dimensionless $C_{p}$ and $C_{p o}$ for various Reynolds number are obtained at different $Z / d h$ for all orifice. Figure 3. shows the $C_{p}$ variation along the circumference of the convex test section for all orifice at $Z / d h=1$. The graphs $C_{p}$ vs $\theta$ revels that the wall static pressure does not depends on the jet Reynolds number as all the curves take same nature for all $\operatorname{Re}(10000-$ 50000 ) with some variation in the $C_{p}$ value at each point, similar independence of $\operatorname{Re}$ over $C_{p}$ and $C_{p o}$ are seen in other works discussed literature review [16-20] but it is observed that the $C_{p}$ and $C_{p o}$ are dependent on dimensionless parameter orifice to test section spacing $(Z / d h)$ which is explained further in present study. 


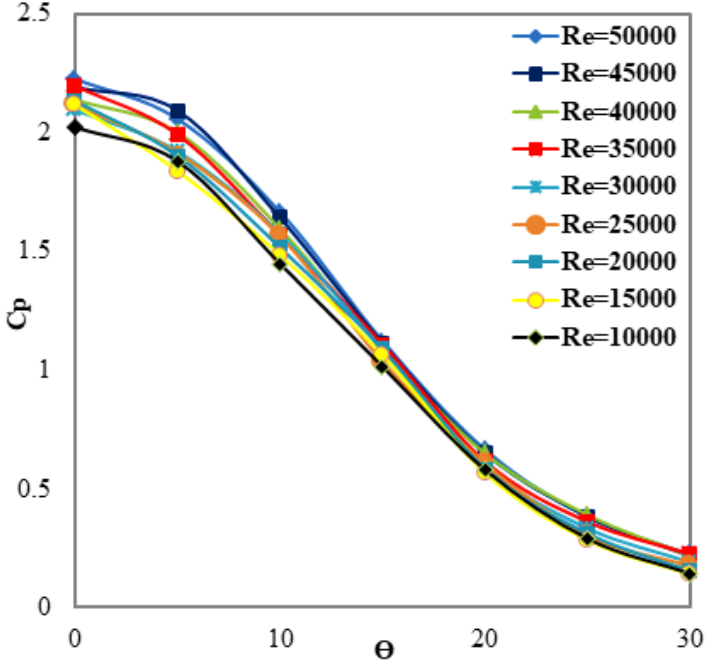

Circular Orifice, $Z / d h=1, D / d h=3.125$

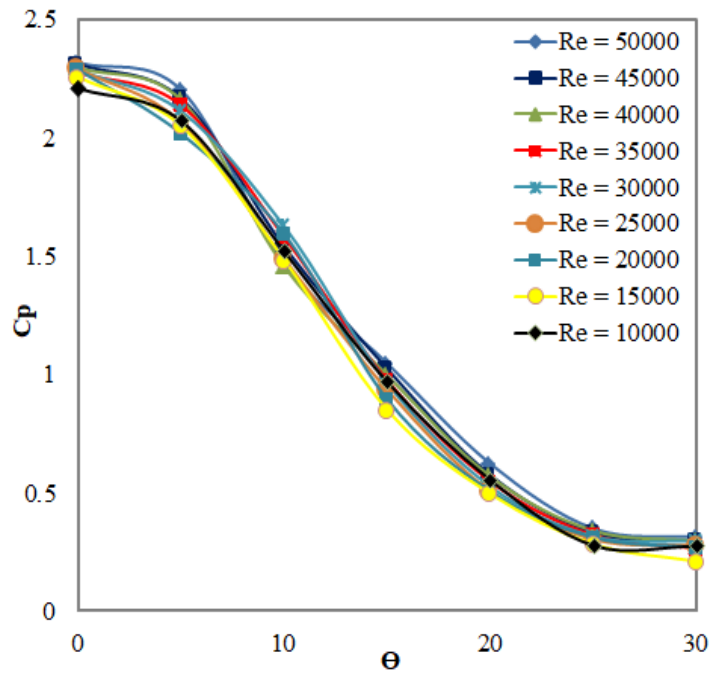

Rectangular Orifice, $Z / d h=1, D / d h=3.125$

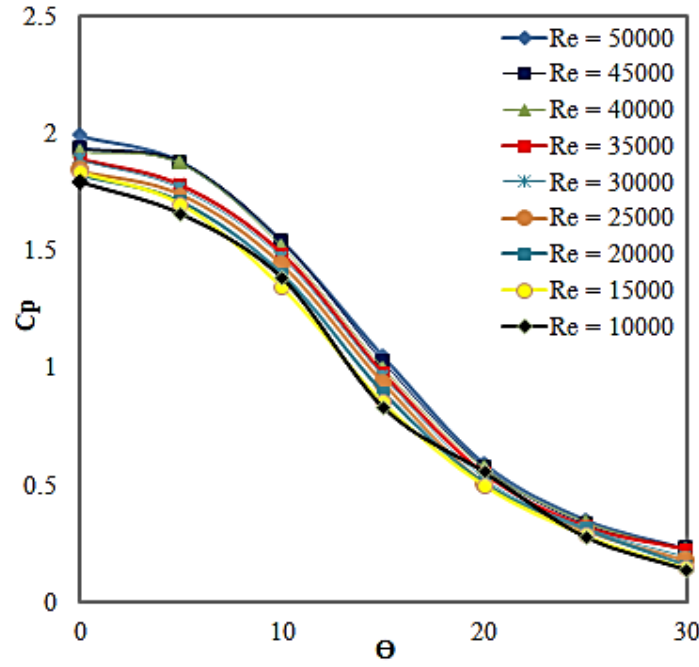

Square Orifice, $Z / d h=1, D / d h=3.125$

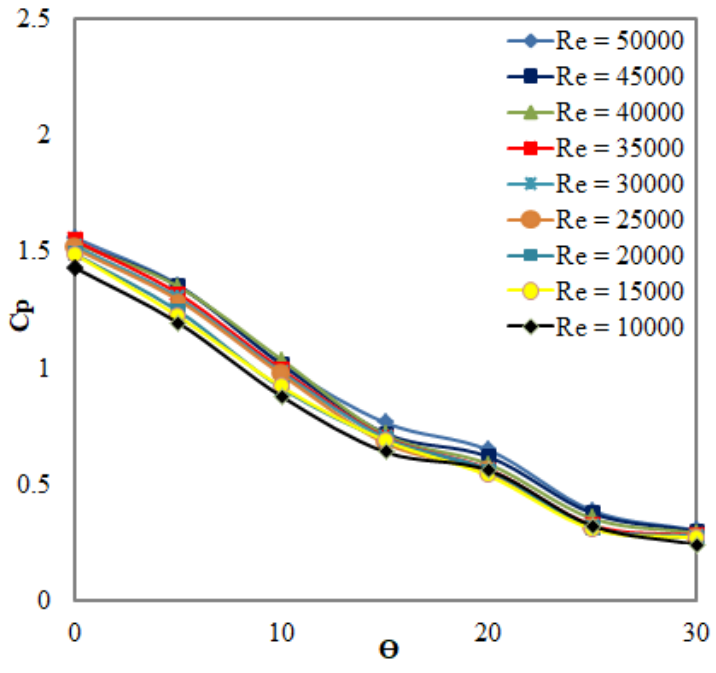

Triangular Orifice, $Z / d h=1, D / d h=3.125$

Figure 3. Variation of Wall Static Pressure Coefficient along the curvature

Influence of Orifice-to-test section (Z/dh) spacing on wall static pressure.

Orifice to test section spacing is another critical parameter that influences the $C_{p o} \& C_{p}$ on any surfaces [17-20]. The Figure $4 C_{p o}$ vs $Z / d h$ and Figure $5 C_{p}$ vs $\theta$ gives a variation of $C_{p o}$ $\& C_{p}$ for various $Z / d h$ ratio. From Figure $4 \& 5$ it observed that as the $Z / d h$ value increases the $C_{p} \& C_{p o}$ drops to a lower value, that is at $Z / d h=5$ the minimum value of $C_{p}$ and $C_{p o}$ are obtained for all the orifices. As the orifice-to-test section spacing increases the jet velocity magnitude decreases due to the spreading of jet, and interaction between jet and surround air becomes more and decreases jet strength due to which the jet falls from sub-atmospheric region to atmospheric region and influences to have lower value of $C_{p} \& C_{p o}$. This spreading of jet is observed from smoke wire flow visualization [2]. 

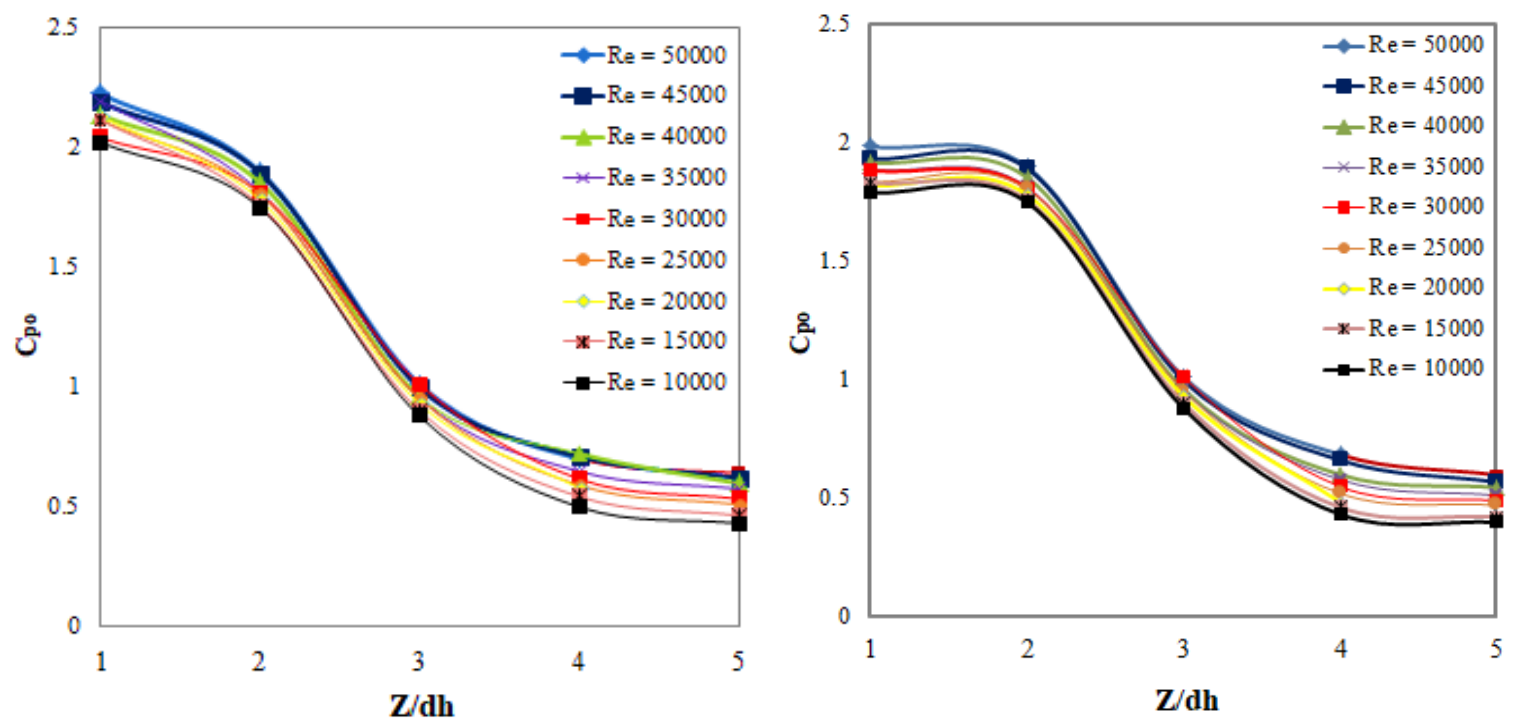

Circular Orifice, $D / d h=3.125$

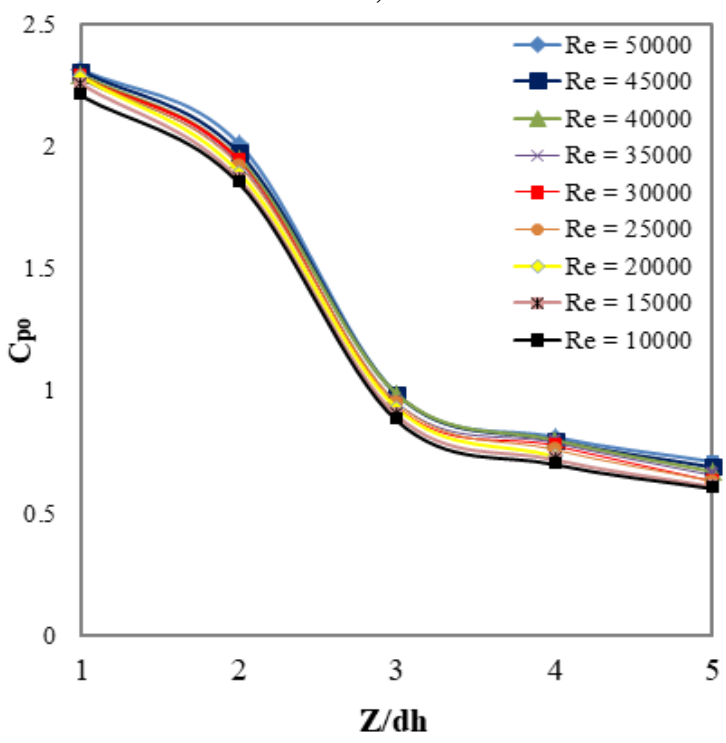

Rectangular Orifice, $D / d h=3.125$

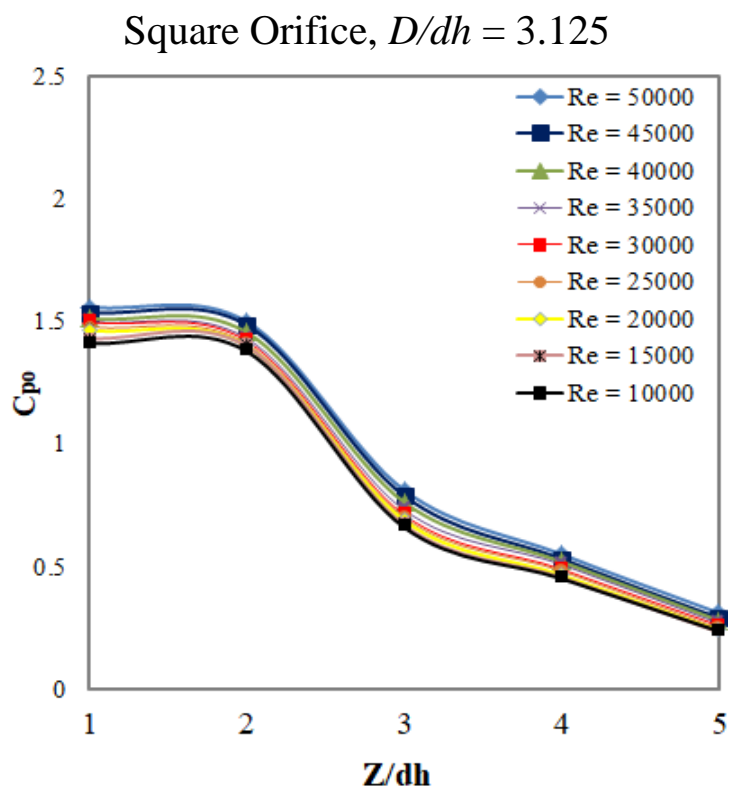

Triangular Orifice, $D / d h=3.125$

Figure 4. Variation of Stagnation Pressure Coefficient with Orifice-to-test section spacing at various Jet Reynolds numbers.

\section{Influence of Circumferential angle $(\theta)$ on wall static pressure.}

The static pressure $C_{p}$ variation along the curvature at different $Z / d h$ is given in the Figure 5 for $R e=40000$ and the same nature is seen for all the jet Reynold number and orifice. As the $\theta$ change the stagnation streamline of jet gets deflected from the centerline of the test section as result $C_{p}$ drops and this jet will have effect on static pressure when its potential core region is between $\theta=0^{\circ}-10^{\circ}$. When $\theta=0^{\circ}$ the test section receives maximum velocity form jet, this velocity helps to get maximum dynamic pressure resulting, stagnation point will reach the maximum value of pressure compared adjacent points on the test section. Similar $C_{p}$ profiles are seen in some of research works [16-19]. 


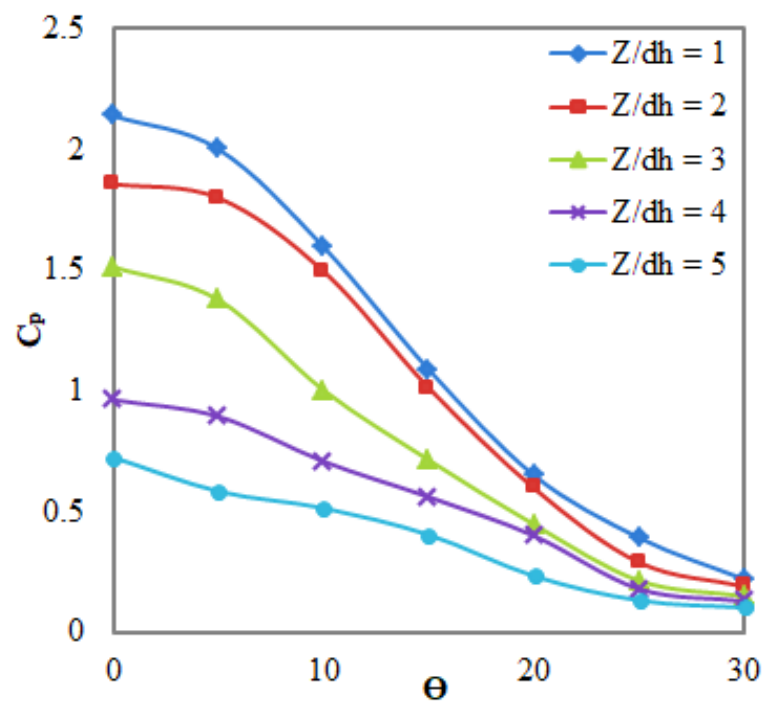

Circular Orifice, $D / d h=3.125$

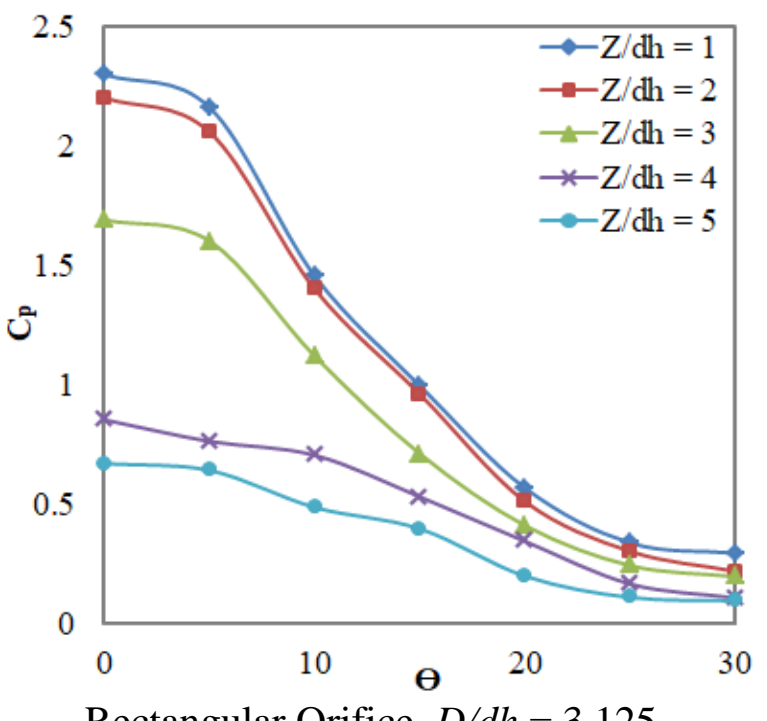

Rectangular Orifice, $D / d h=3.125$

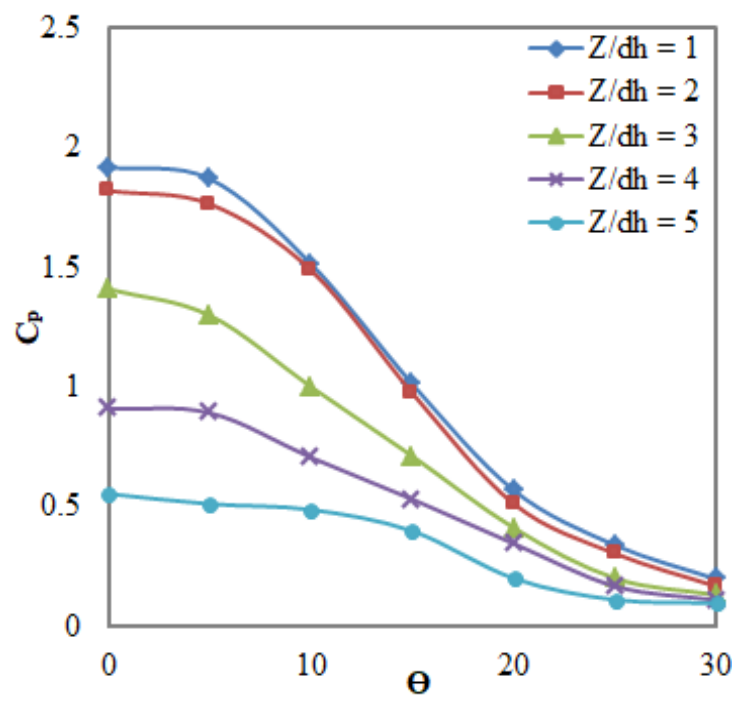

Square Orifice, $D / d h=3.125$

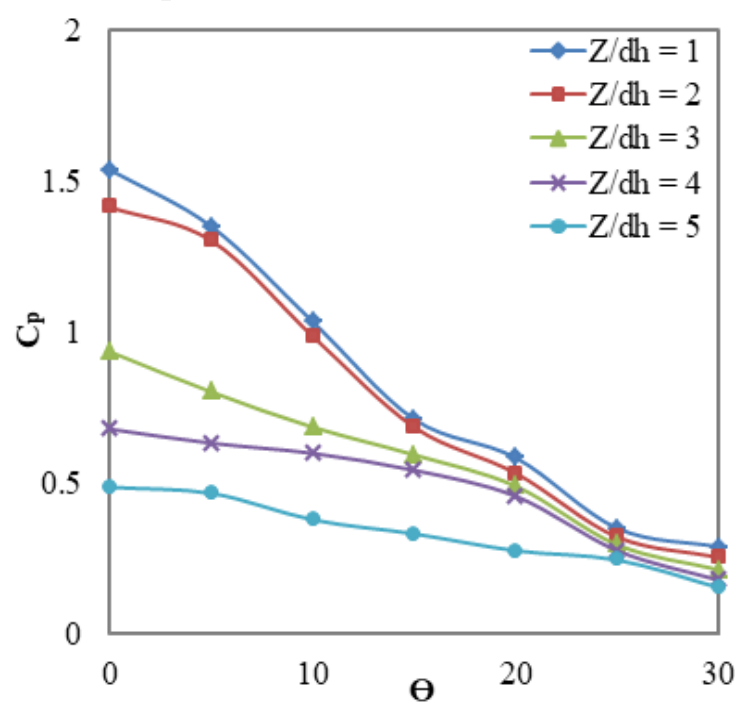

Triangular Orifice, $D / d h=3.125$

Figure 5. Variation of Static Pressure Coefficient with curvature at various Orifice-to-test section spacing.

\section{Comparison of wall static pressure for different orifice.}

The main and prior objective is to know the effect of orifice geometry on wall static pressure coefficient on convex surface. The comparison of $C_{p o} \& C_{p}$ for all orifices at particular $Z / d h$ and $R e$ is shown in the Figure 6. From comparison graph it's clear that the rectangular orifice gives a higher value of $C_{p o} \& C_{p}$ when compared to other orifice at lower $Z / d$. This may be because turbulent intensities at orifice exit are of high and are carried to stagnation zone for rectangular orifice. As Z/dh increases the $C_{p o} \& C_{p}$ values for circular, square and rectangular orifice are appreciably in the same range, whereas $C_{p o} \& C_{p}$ for triangular orifice completely deviated from other orifice and the same trend is noticed for all jet Reynolds number $(R e)$ and $\mathrm{Z} / \mathrm{dh}$. 

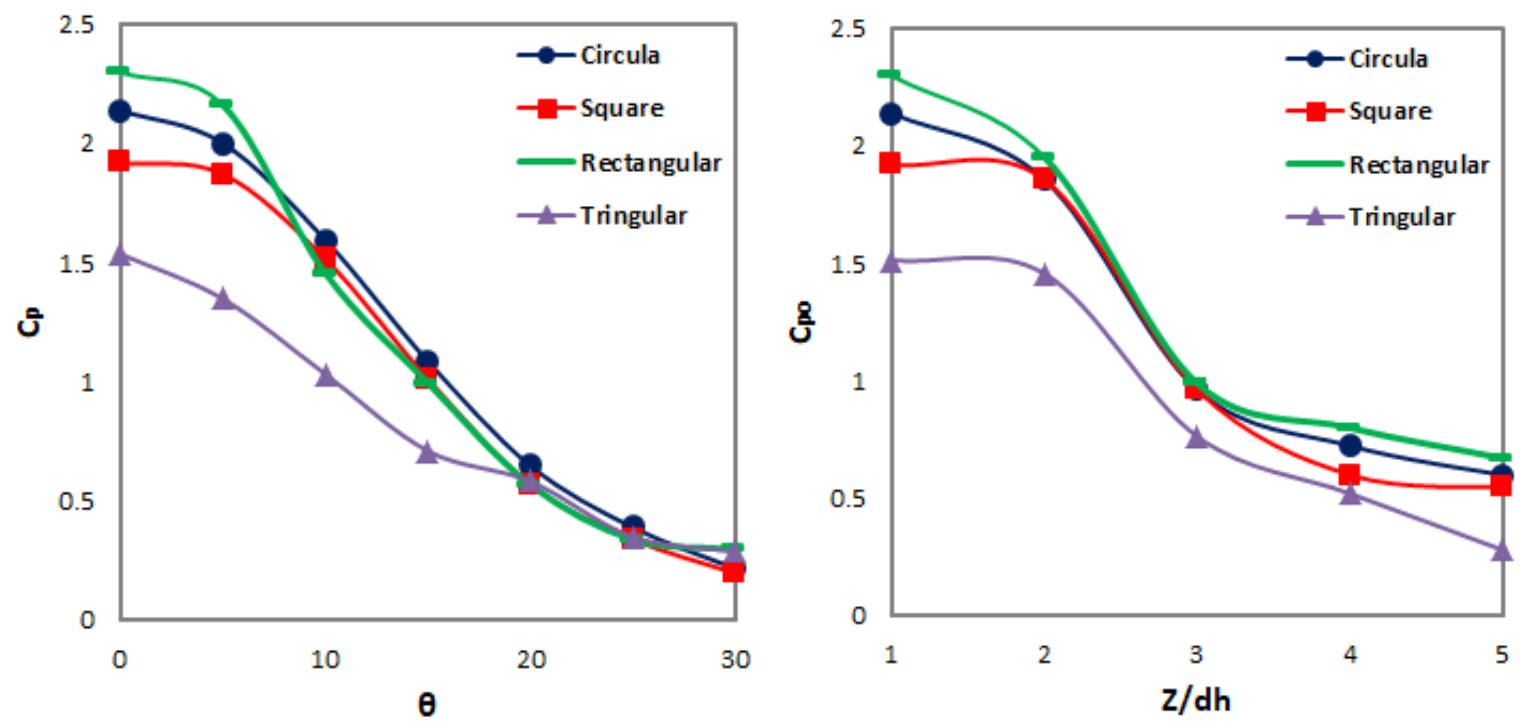

Figure 6. Comparison of wall static pressure $C_{p o} \& C_{p}$ for different orifice at $Z / d h=1$, $\operatorname{Re}=40000$.

\section{Pressure loss coefficient $\left(P_{c}\right)$ Study for different orifice.}

The pressure-loss-coefficient $\left(P_{c}\right)$ for all orifice at various $Z / d h$ are analyzed in present study. The Figure 7 shows variation of pressure loss coefficient for all orifice-to-test section spacing (Z/dh) at different jet $R e$ ranging from 25000 to 50000 . The similar analysis is carried by P. Gulati et al. [5] for concave surface with some different nozzle profile. Pressure-losscoefficient $P_{c}$ for circular orifice is low and for triangular orifice is high compared to other orifice used in the study, that is $P_{c}$ for Circular $>$ Square $>$ Rectangular $>$ Triangular. From this analysis it is clear that the triangular orifice requires maximum pumping power compared to other orifice where as for the circular orifice requires least pumping power. 


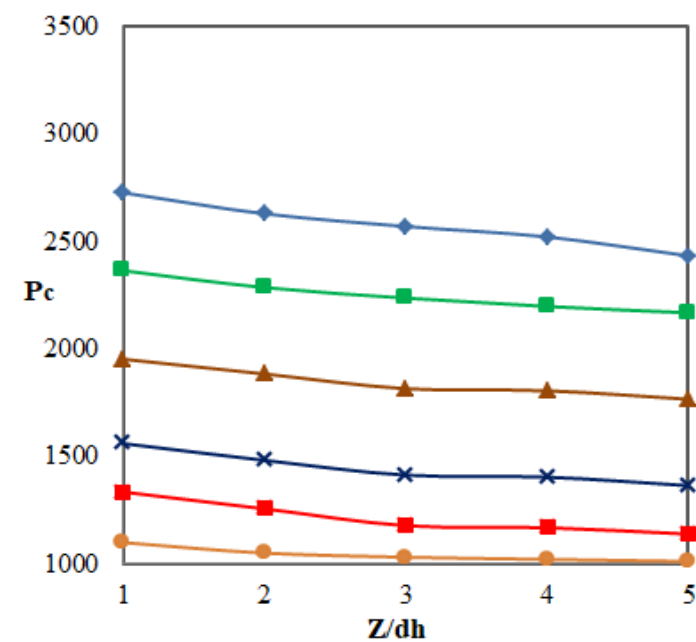

$\leadsto-\mathrm{Re}=50000 \rightarrow-\mathrm{Re}=45000 \multimap \mathrm{Re}=40000$

$\rightarrow$ * Re $=35000 \rightarrow-\mathrm{Re}=30000 \multimap-\mathrm{Re}=25000$

Circular Orifice

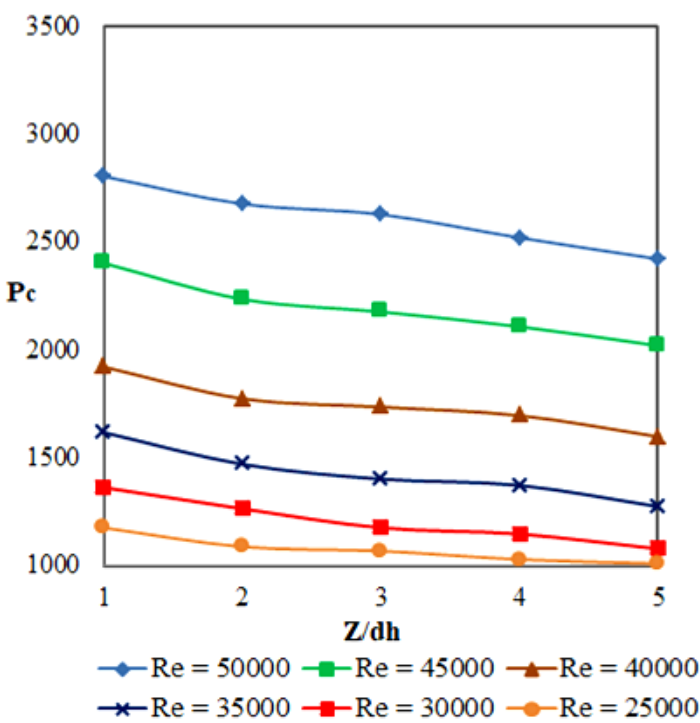

Rectangular Orifice

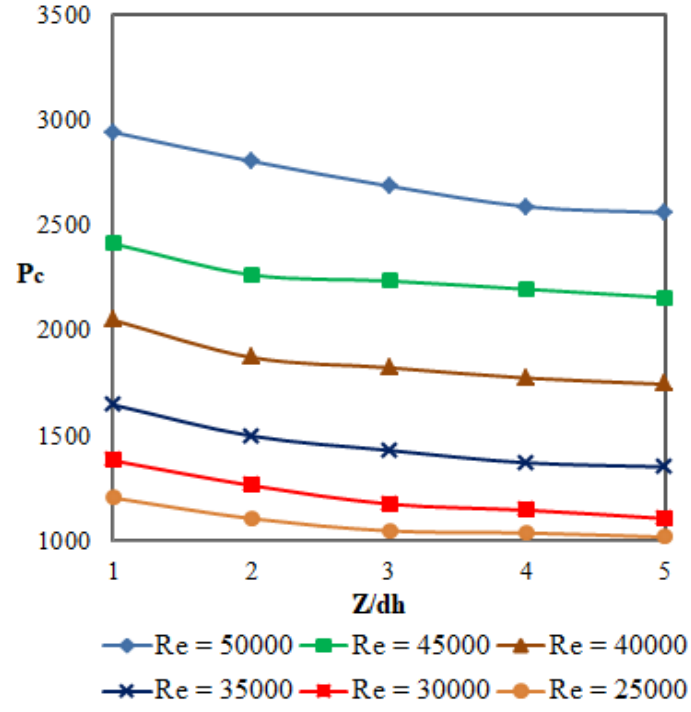

Square Orifice

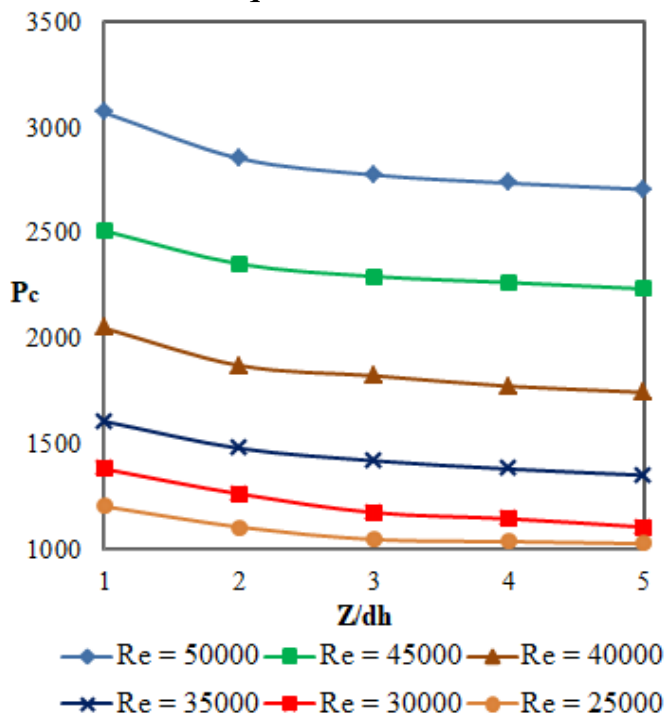

Triangular Orifice

Figure 7. Variation $P_{c}$ with Orifice-to-test section spacing at various Jet Reynolds numbers for orifice. 


\section{CONCLUSIONS}

The Experimental determinations of effect of orifice geometry and orifice-to-test section spacing on distribution of $C_{p} \& C_{p o}$ on convex surface due to an air jet impingement from different orifice for unconfined flow at different geometric and flow parameters is studied. The results will help in the study of heat transfer distribution and also play significant role in the design and analysis of gas turbine blades.

After a number of experiments at steady state condition the following conclusions are obtained from wall static profile.

- $\quad$ The wall static pressure $C_{p} \& C_{p o}$ are independent of Jet Reynolds Number of flow on impingement of air jet from the orifice on the convex surface for particular $Z / d h$.

- $\quad$ The value of the wall static pressure $C_{p} \& C_{p o}$ on convex surface are almost uniform up to $\theta=10^{0} \&$ at higher values of $\theta, C_{p} \& C_{p o}$ decreases considerably for all orifices.

- $\quad$ For the same Jet Reynolds number of flow, the wall static pressure $C_{p} \& C_{p o}$ are high for Lower orifice-to-test section spacing $(Z / d h=1)$ compared to higher $Z / d h$.

- $\quad$ The higher value of $C_{p} \& C_{p o}$ are noticed for rectangular orifice.

- $\quad$ The lower value of $C_{p} \& C_{p o}$ are noticed for triangular orifice.

- $\quad$ The pressure-loss-coefficient $\left(P_{c}\right)$ is low for triangular orifice and high for circular orifice for same flow condition.

- $\quad$ The rectangular orifice is more suitable compared to other orifice used in the present study and orifice to test section spacing less than two $(Z / d h=2)$ will have greater effect on the wall static pressure distribution.

\section{REFERENCES}

[1] Cristina Cornaro, Amy S. Fleischer, Michael Rounds, Richard J.Goldstein. Jet impingement cooling of a convex semi-cylindrical surface. International Journal of Thermal Sciences 2001; 40(10): 890-898.

[2] A. S. Fleisher, K. Kramer, R. J. Goldstein. Dynamics of the vortex structure of a jet impinging on a convex surface. International Journal of Thermal and Fluid science 2001; 24(3): 169-175.

[3] Chang Shyy Woei, Jan Yih Jena, Chang Shuen Fei. Heat transfer of impinging jetarray over convex-dimpled surface. International Journal of Heat and Mass Transfer 2006; 46: 3045-3059.

[4] D.W. Zhou, Sang-Joon Lee. Forced convective heat transfer with impinging rectangular jets. International Journal of Heat and Mass Transfer 2007; 50(9-10): 1916-1926.

[5] Puneet Gulati, Vadiraj Katti, S.V. Prabhu. Influence of the shape of the nozzle on local heat transfer distribution between smooth flat surface and impinging air jet. International Journal of Thermal Sciences 2009; 48(3): 602-617.

[6] Dushyant Singh, B. Premachandran, Sangeeta Kohli. Effect of nozzle shape on jet impingement heat transfer from a circular Cylinder. International Journal of Thermal Sciences 2015; 96: 45-69. 
[7] Xuan Thao Trinh, Matthieu Fénot, Eva Dorignac. The effect of nozzle geometry on local convective heat transfer to unconfined impinging air jets. Experimental Thermal and Fluid Science 2016; 70: 1-16.

[8] Y. Karakus, A. Jabbarli and D. Erdem. Effect of non-circular nozzle shape on impingement cooling Characteristics. In: 7th European Conference For Aeronautics And Space Sciences (EUCASS), Italy; 3-6 July, 2017.

[9] S. Abraham, R.P. Vedula. Effectiveness distribution measurements for a row of heated circular jets impinging on a cylindrical convex surface at different inclinations. International Journal of Heat and Fluid Flow 2018; 69: 210-223.

[10] Abraham, S., Kakade, A.B., Vedula, R.P. Convex Surface Heat Transfer Behaviour in the Presence of Obliquely Impinging Non-Isothermal Slot Jets. In: Proceedings of the World Congress on Engineering, London, U.K;1273-1278; 2015.

[11] D. Lytle, B.W. Webb. Air jet impingement heat transfer at low nozzle plate spacings. International Journal of Heat and Mass Transfe 1994; 37(12): 1687-1697.

[12] V. Katti, S.V. Prabhu. Experimental study and theoretical analysis of local heat transfer distribution between smooth flat surface and impinging air from a circular straight pipe nozzle. International Journal of Heat and Mass Transfer 2008; 51(1718): 4480-4495.

[13] Vinze R., Chandel S., Limaye M.D., Prabhu S.V. Influence of jet temperature and nozzle shape on the heat transfer distribution between a smooth plate and impinging air jets. International Journal of Thermal Sciences 2016; 99: 136-15.

[14] D. Singh, B. Premachandran, S. Kohli. Numerical simulation of the jet impingement cooling of a circular cylinder. Numerical Heat Transfer, Part A: Applications An International Journal of Computation and Methodology 2013; 63(2): 153-185.

[15] D. Singh, B. Premachandran, S. Kohli. Experimental and numerical investigation of jet impingement cooling of a circular cylinder. International Journal of Heat and Mass Transfer 2013; 60(1): 672-688.

[16] Prof. A. M. Hanchinal, Krishna Alias Aditya B., Rahul Torgal, Naveed Sudarji, Aishwarya Chhapre. Study on Impingement of Air Jet from Orifice on Convex Surface for Unconfined Flow. International Journal for Research in Applied Science and Engineering Technology 2018; 6(5): 2628-2633.

[17] A Hanchinal, K Ramadurg, RN Patil. Experimental Investigation of Effect of Curvature Ratio on Coefficient of Static Pressure Disrtribution on the Concave Curved Surface due to Impingement of Air Jet from An Circular Orifice of Dia 10mm for Confined Flow. International Journal of Engineering Technology Science and Research 2017; 4(1): 80-85.

[18] K Ramadurg, A Hanchinal, RN Patil. Experimental Investigation of Coefficient of Static Pressure Distribution on the Concave Curved Surface due to Impingement of Air Jet from an Orifice (For $\mathrm{D}=14 \mathrm{~mm}$ ) for Confined Flow. International Journal of Engineering Technology, Management and Applied Sciences 2017; 5(1): 123-128.

[19] V.S. Patil, R.P. Vedula. Local heat transfer for jet impingement on a concave surface including injection nozzle length to diameter and curvature ratio effects. Experimental Thermal and Fluid Science 2018; 92: 375-389.

[20] Vadiraj Katti, S. Sudheer, S.V. Prabhu. Pressure distribution on a semi-circular concave surface impinged by a single row of circular jet. Experimental Thermal and Fluid Science 2013; 46: 162-174. 